\title{
The Impact of Management Science in the University on the Professor's Life Style
}

Bertrand L. Hansen *

A recent report of a major study of the higher education system in the Province of Ontario contains an hypothetical model change to financing the instructional sector of the university as follows : ${ }^{1}$

$$
I_{c}^{\prime}=\frac{\left(S_{c}^{t}\right)\left(S L_{c}^{t}\right)}{\left(C_{c}^{t}\right)\left(P_{c}^{t}\right)\left(F L_{c}^{t}\right)}
$$

Can you picture the reaction of the academic community to this suggestion? The scientists and engineers will of course want to delve deeper into the proposal ; the humanities professors will be horrified by the thought that anyone would try to reduce the university to an algebraic equation. All professors will be troubled about the simplistic approach this represents to planning for higher education. In any event, this approach to university planning has far-reaching implications for academics whatever their calling.

Overall there will be changes in the professor's life style resulting from a combination of factors, with the major ones being the relatively high level of public resources being consumed by higher education, the multitude of competing demands for limited financial resources, the pressures from students for change, and the advances in the state of the art of information science and management science in funding agencies and universities.

Operations research activities have been developing a foothold in the universities for some time. You can't do research without data. Substantial resources are being poured into external data bank and information design agencies such as WICHE in the United States and in various provincial, interprovincial and federal organizations in Canada. Information is being upgraded in universities. Institutional research and planning offices at high administrative levels in the university are becoming the rule rather than the exception.

* Bertrand L. Hansen is Director of Research for the Council of Ontario Universities and Associate Professor of Higher Education, University of Toronto. 
Interest in institutional research is of course not that recent. For example, in 1961 I moved out of an aerospace management systems to establish an institutional research office at the University of Toronto with the major activity being the development of a Rand-type logistics model to the allocation of university resources. At that time Koenig was developing a model at Michigan State as was George Weathersby at California. Many of you will be familiar with the development of simulation models for university planning (CAMPUS, RRPM, Plan'Tran, Weathersby's cost simulation model). Most early applications were of the simulation variety because of difficulty in constructing an objective function. In the years since there has been a considerable growth in institutional recognition of the resource planning function. More recently there have been other applications of Operations Research to university planning - for example, two recent doctoral theses at the University of Toronto have dealt with the application of linear programming to university planning. There are many more applications of a more mundane variety - programme costing and budgeting, cost/benefit and tradeoff analysis, multiple regression analysis, exponential smoothing - which are being applied routinely in the planning activities of universities and funding agencies:

The reasons for these developments are that decision-makers at all levels must put pieces of information together to be able to make rational choices. The pressures from funding agencies for management decision information results in pressures directed downward to university administration, through the university hierarchy to where it stops at the level of the department, the professor and his activities.

The professor cannot help but be affected. If we exclude money, in which we are all interested, historically he has valued, possibly in order of preference, (1) the relative freedom to manage his own time for a fair portion of the day and year, (2) the relative freedom to say what he thinks, (3) the opportunity to interact with faculty peers and bright students in an intellectually stimulating environment, (4) the psychic income of self actualization - the highest in the Maslow hierarchy of human needs and (5) related to the previous one, the knowledge that he is providing benefit to society through his students. Currently he is finding that along with limited funding from unsympathetic agencies, which tends to restrain his salary increases and threaten his life style, he is asked to provide information on teaching contact hours, class sizes, time he spends on research, and so on ad nauseam.

Programme budgeting has transferred a part of its ugly head from the Department of Defense to Higher Education. Thus, planning and control information is being asked for by programme, level of programme, resource inputs, cost and product outputs. Also, legislatures, (as for example the Michigan legislature) are beginning to approve bills to require a minimum number of contact hours from professors. The administrative bureaucracies in government and universities build staff to request, sift and analyze information; and the net result of all of this looks to the professor like more teaching hours and less freedom to manage his own time outside the classroom. In return for 
his cooperation in providing information, his salary increases are likely to be less or zero. He may even be asked to take a cut ; to prevent this happening he may have to jump on the collective bargaining bandwagon.

As a group, professors will stack up well with any other profession in the devotion of time to work and service. People on the outside who are envious of his aforementioned values and perquisites (especially his peers in government) resent these aspects of life; and in true egalitarian fashion, they are exerting pressures to change it. I suspect that faculty workload is not the real issue - the real issues may be the relative freedom of the academic from externally-imposed time requirements and his distribution of time to work activities. Supplementing this, and of course playing into the hands of the new equalizers, is the seeming poor performance in productivity over the past couple of decades. The fact that this is true of any labour intensive sector, government included, is immaterial; that productivity must take the quality of the output into account is ignored. No matter that in return for the "savings" deriving from one more contact hour on the lecture platform there is another offsetting "cost effectiveness" unit created somewhere in the bureaucratic hierarchy.

Also, at the seat of the disaffection of a government and the public with the academic community is the belief that universities cannot manage their own affairs. One influential critic has proposed that job descriptions, evaluation standards, and time standards should be imposed on academics. While I don't think we will come to this for a while yet, it is symptomatic of the feeling of people on advisory boards and in funding agencies.

The formula cited above and others of the same genre are intended to exert pressures toward the accomplishment of these purposes without actually stepping in and taking over the management. (Parenthetically, it is worth mentioning that another proposal in the same report amounted essentially to a government takeover of high level university management. One president commented that he could look forward to managing parking lots if this proposal were implemented.)

Let us delve deeper into the proposed operating grants of instruction formula, in order to see what it means and what it is likely to cause in the way of organized response of an antagonistic nature and pressures for data collection necessary to implement it.

The notation of the variables is as follows :

$$
\begin{aligned}
\mathrm{I}_{\mathrm{c}}^{\prime}= & \text { new income per student for. the enrolment category } \\
\mathrm{S}_{\mathrm{c}}^{\mathrm{t}}= & \text { average annual faculty salary for the category } \\
\mathrm{SL}_{\mathrm{c}}^{\mathrm{t}}= & \text { average student contact hour load per week for. each } \\
& \text { category } \\
\mathrm{C}_{\mathrm{c}}^{\mathrm{t}}= & \text { average class size for the enrolment category: . }
\end{aligned}
$$




$$
\begin{aligned}
\mathrm{P}_{\mathbf{c}}^{\mathrm{t}}= & \text { percent of income allocated to faculty salaries for the } \\
& \text { category } \\
\mathrm{FL}_{\mathbf{c}}^{\prime t}= & \text { new average faculty contact hour load per week for } \\
& \text { each category }
\end{aligned}
$$

Spelled out, then, the formula becomes

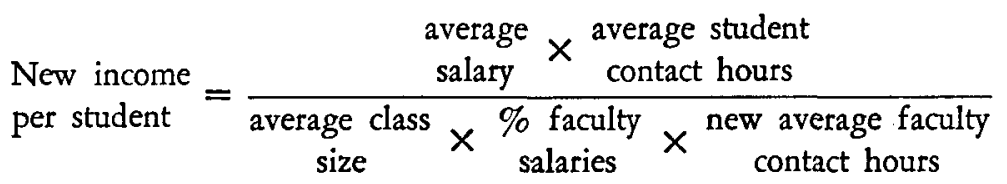

Let us assume present values for the variables for the category of general arts and science are

$$
\begin{array}{ll}
\mathrm{S}_{c}^{t}=\$ 13 ; 200 & \mathrm{P}_{\mathrm{c}}^{\mathrm{t}}=.45 \\
\mathrm{SL}_{\mathrm{c}}^{\mathrm{t}}=20 & \mathrm{FL}_{\mathrm{c}}^{\mathrm{t}}=9.6 \\
\mathrm{C}_{\mathrm{c}}^{\mathrm{t}}=37 &
\end{array}
$$

Then,

$$
\begin{aligned}
I_{c} & =\frac{\$ 13,200 \times 20}{37 \times .45 \times 9.6} \\
& =\$ 1650, \text { the present income per student }
\end{aligned}
$$

To derive new incomie per student it is proposed by the Report that faculty contact hours would be increased arbitrarily to 13 , and all other variables held constant. The new income per student is

$$
\begin{aligned}
I_{c}^{\prime} & =\frac{\$ 13,200 \times 20}{37 \times .45 \times 13} \\
& =\$ 1,218
\end{aligned}
$$

The student/faculty ratio for the original case is

$$
\begin{aligned}
S_{c}^{t} & =\frac{\left(C_{c}^{t}\right)\left(F L_{c}^{t}\right)}{\left(S L_{c}^{t}\right)} \\
& =\frac{\begin{array}{c}
\text { average class } \\
\text { size }
\end{array} \times \begin{array}{c}
\text { average faculty } \\
\text { contact hours }
\end{array}}{\begin{array}{c}
\text { average student } \\
\text { contact hours }
\end{array}} \\
& =\frac{37 \times 9.6}{20} \\
& =17.8
\end{aligned}
$$


For the new proposal, it is

$$
\begin{aligned}
S_{c}^{\prime t} & =\frac{37 \times 13}{20} \\
& =24
\end{aligned}
$$

This prosal is defended in a footnote where it is suggested that with two preparation hours for every contact hour there would be a thirty-nine hour instructional work week. ${ }^{2}$ The Report also suggests that the money released by the changes to all categories (about 30\% of present operating funds) should be considered as university research money which would be distributed to professors and teams of university researchers who would put the money to the best use. It would, therefore, separate so-called university research from the traditional funding formula, according to which universities can distribute funds internally as they see fit, with research now to be funded by otber criteria determined by agencies external to the university.

Academics will immediately perceive the threat to one of their cherished values - this move would begin to erode the relative freedom to manage a large portion of their own time. What matters freedom if it exists for only a small portion of the time and only a small proportion of professors? Instead of his having to make his case to his department and division heads, the professor will now have to make his case for research time and money to an external funding agency. The chase for this research money (well over $\$ 100$ million in Ontario) and the bureaucratic machinery that would have to be set up at all levels would certainly change the character of our universities ; it could well destroy 'several of the newer ones.

The professor's view of administration is important in attempting to assess his reaction to increasing demands from external agencies. Earlier I alluded to the university hierarchy; but the professor generally does not recognize a hierarchy - he prefers to think in terms of oligarchies or collegiums. In the December 71 issue of Management Science, reporting on a survey of operations of academic departments, Hobbes and Anderson say that "No one who was interviewed stated, or even implied, that faculty members serving in administrative capacities either gave orders to other faculty or received orders from 'superiors' : consultation and coordination were the strongest terms used to describe the interactions of departmental administrators with other departmental members. Administrative activities per se were consistantly spoken of as services rendered the department by faculty, not jobs for which 'adminitrators' were hired. ... Administrative labour in academic departments is distributed among the faculty, who conduct themselves in their administrative roles as equals, not superiors, of their colleagues. ... Faculty do not see themselves as subordinates in a hierarchy who are obligated either by duty or by sanction to respond affirmatively to every administrative action of other faculty in the department. Consequently, they take their conflicts with departmental administrators not 'up' a hierarchical ladder but to the applicable organizational structure in which the governance concerning the issue in conflict is pursued." 
The structure is of course the peer group. This poses severe problems; to which I can attest from attempts to secure good data. Thus, in asking for data I make sure I am soliciting it as a member of the peer group emphasizing that centrally we will deal mainly with improving definitions of programmes and data elements; that data are maintained at source; and that we function not by directive but by collective, collegial action in response to a perceived threat from the government and the legislature. To do otherwise is to invite game playing, data which are garbage, outright refusal and a possible retreat to collective bargaining.

I have described briefly the administrative and organizational threats that are now deriving from the centralization of decision-making formerly carried out at the departmental level. What is the impact of conceptualizing a model which requires data input for application? It is possible to apply a macro-formula which would not differentiate among categories of programmes. In fact, elementary and secondary school macroformulas based on class size and pupil-teacher ratios are in common use. If this were the case for universities, average values over-all categories could be determined for student contact hour load, salary, faculty contact hour load, class size, academic salaries, and proportion of budget. University presidents and deans would like this kind of formula ; it gives them distribution authority. For this reason, neither legislatures nor academics would like it ; legislatures because the current perceived needs of society would not be served well by tradition-oriented university, managers, and faculty because they realize that egalitarian pressures would tend to cause real differences in programme costs not to be tecognized.

Thus, pressures are set up to develop and refine the programme taxonomy; to establish data element definitions and procedures for collecting the required data by programme to feed the model. Organizations and procedures need to be structured. Data banks must be established. An information engine is built which tends to increase in complexity with developments in the state of the art. As with all non-standardized activities, of course, the very greatest problems are with programme definition and data element definition. In absence of agreed-upon criteria for each of these, information becomes distinctly non-neutral (it is never neutral) and game playing to maximize some departmental or personal academic objective becomes the rule. Also, the engine must be fed, and with increasingly more expensive fuel to cause it to do more things for more administrative people. Double bookkeeping systems are set up because the green eyeshade people don't trust the new number crunchers.

All of this has great implications for the faculty member and department chairman who have the kind of stereotyped view of administration described by Hobbs and Anderson. The most profound impact will be on the department chairman. He cannot be a peer among peers performing a service for his colleagues at the same time that he is interpreting and passing on demands for more and more information about the activities of his colleagues. In this, as a collective bargaining, we may begin to see the separation 
of the men from the boys, i.e., the separation of management and labour. It seems to me that here the conflict is the greatest. I do not believe that a department chairman can remain a peer in the collegial organization of the department and still meet the information demands that will be placed upon him.

I have been cautious to limit my discussion to the impact of management science on the life style of the professor. As you will have seen, I do not interpret developments in management science as making the professor's job happier in the future. By the same token, given the changes in the greater society which forms his environment I am not sure that it could be any different. Opportunity cost is a factor to be reckoned with in any judgment process. Further, I wouldn't say that there shouldn't be some erosion of academic values.

I used to think that our problems would be solved if we could only entice more systems analysts away from the aerospace programme. I don't now. We have a logistics management problem. Our resources are sufficient overall (maybe an over-supply) but inflexible. We need much more flexibility in our resources. To put it bluntly, not all physics professors should be teaching physics for all their lives. We need a programme/ resource matrix organization at the department level which retains the benefits of the collegium while offering other benefits of rapid logistical support. We need progressive management and incentives to changes. We need not so much management science as management leadership.

Higher education has grown at unprecedented rates in the past two decades. There is a perception that it needs to be harnessed ; university autonomy and academic freedom in universities will be displaced in the process. The professor will suffer the most as a consequence of this displacement because he has the most to lose. If this loss results in real progress toward solutions of our problems in higher education it will have been worth it. If it results in simply a transfer of costs to administrative units, with no benefit it will not. I wish I could be more optimistic. As I mentioned before I am in favour of working at the grass roots level simply because I don't think the creation of more bureaucratic units will result in direct benefits. Traditional attitudes and values must change or there will be no real progress. And getting this kind of change in our universities will be a slow laborious process. Many people in the academic community are dead-set against such changes. The crucial issue is whether we can keep our universities critical and free in the face of the conflict of pressures arising from intense social demand for change and academic resistance to changing traditional values.

Notes

1. Draft Report of the Commission on Post-Secondary Education in Ontario. The Queen's Printer, Toronto, 1972. Appendix E, Analysis of Unit Income and Expenditure in Post-Secondary Education, pp. 108-112, esp. p. 110.

2. Op. cit., p. 112 . 